Research Article

\title{
Failure Behavior and Energy Storage and Release of Hard Coal under Different Static and Dynamic Loading States
}

\author{
XianJie Hao $\mathbb{D}^{1,2,3,4}$ GuangYao Pan $\mathbb{D}^{4},{ }^{4}$ Chaoxing Ma $\left(\mathbb{D},{ }^{5}\right.$ Yingnan Wei $\mathbb{D}^{4},{ }^{4}$ \\ and Zeyu Chen (D) $^{4}$ \\ ${ }^{1}$ State Key Laboratory of Water Resource Protection and Utilization in Coal Mining, Beijing 100083, China \\ ${ }^{2}$ Beijing Key Laboratory for Precise Mining of Intergrown Energy and Resources, \\ China University of Mining and Technology (Beijing), Beijing 100083, China \\ ${ }^{3}$ Key Laboratory of Safety and High-Efficiency Coal Mining, Ministry of Education (Anhui University of Science and Technology), \\ Huainan 232001, China \\ ${ }^{4}$ School of Energy and Mining Engineering, China University of Mining and Technology (Beijing), Beijing 100083, China \\ ${ }^{5}$ Oil Production Plant No. 11, Changqing Oilfield Company, Xi'an 710018, China
}

Correspondence should be addressed to XianJie Hao; haoxianjie@cumtb.edu.cn

Received 14 August 2020; Revised 24 September 2020; Accepted 26 September 2020; Published 23 October 2020

Academic Editor: Fengqiang Gong

Copyright (c) 2020 XianJie Hao et al. This is an open access article distributed under the Creative Commons Attribution License, which permits unrestricted use, distribution, and reproduction in any medium, provided the original work is properly cited.

\begin{abstract}
The study of the energy accumulation and rate of release in hard coal under dynamic, static, and coupled dynamic-static loading and its failure mode is of significance when studying the mechanism underpinning coal mine dynamic disasters such as rock burst, coal, and gas outburst. In this paper, four experimental methods (uniaxial compression, Brazilian splitting, and coupled dynamic-static tensile and coupled dynamic-static compression) were used to analyze the energy accumulation, energy rate of release, and failure modes of this type of hard coal under different loading conditions. It was concluded that (1) the energy accumulation and rate of releases of this type of hard coal under static compression are 17.63-179.90 times and 18.57-13157.89 times those under static tension; the energy accumulation and rate of releases in dynamic compression are 2.11-248.53 and 0.23-48 times those under dynamic tension, respectively. (2) During dynamic loading, the ratio of compressive energy accumulation to tensile energy accumulation is reduced by 1.6 times compared with static loading, and the ratio of compressive energy release to tensile energy rate of release is decreased by 363.84 times compared with static loading. (3) The energy accumulation and rate of releases of this type of hard coal for dynamic tensile are, respectively, 2.64-17.42 and 1.07-5.26 times those under static tensile load; the energy accumulation under dynamic compression is greater than that under static compression, being 0.24-15.04 times that under static compressive, but the energy rate of release under dynamic compression is $0.0003-0.56$ times that under static compression. (4) The greater the prepeak energy accumulation, the greater the degree of damage of the coal sample at each stage, and also the higher the degree of fragmentation after the failure. The research results play an important guiding role in further understanding the mechanism of coal mine dynamic disasters.
\end{abstract}

\section{Introduction}

With the increase in the scale of shallow coal mining, coal mining has gradually developed to a greater depth, and coal masses are more severely affected by high stress and mining disturbance, therefore, studying the energy accumulation and release and failure modes of coal under dynamic, static, and coupled dynamic-static loading is useful for revealing the mechanism underpinning coal mine dynamic disasters such as rock bursts $[1,2]$, roof falls $[3,4]$, and coal gas outbursts $[5,6]$.
Many scholars have used various research methods to investigate the accumulation and release of coal energy in response to the occurrence and development of coal mine dynamic disasters. Wu et al., with the mechanics experimentations of coal samples, analyzed different flexibility energy and researched quantificationally [7]. Zhang et al. conducted a numerical modelling study to evaluate the roles and contributions of different energy components [8]. Vardar et al. employed the Universal Distinct Element Code (UDEC) trigon method incorporating inherent discontinuities to 
investigate the changes in the pre- and postpeak behavior as well as the energy release characteristics of different coal mass samples [9]. Hao et al. used the stress-strain curve of the uniaxial compressive test to establish a new bursting liability evaluation index for coal [10]. Hao et al. considered unsteady energy release at the postpeak stage and establish a new brittleness index for hard coal [10]. Tang et al. obtained the stress thresholds of coal that were in uniaxial and triaxial compression, discussed the energy evolution during the compression, and coupled with the crack volumetric strain [11]. Zhang et al. considered the effects of depth on the in situ stress environment and physical properties of coal and conducted triaxial compression experiments on 128 coal samples that were on this basis, showing that, with increasing depth, the elastic energy and dissipated energy increase more rapidly [12]. Lan et al. established the coal and rock system model based on the tectonic stress and showed that the trend of released energy of damaged coal has good consistency with the variation of permeability, and water injection can reduce the stress concentration and energy concentration of the rock burst system [13]. Feng et al. studied the relationship between stress-strain, uniaxial compressive strength, displacement rate, loading rate, fractal dimension, and energy dissipation rate through static loads and dynamic loads experiment [14]. Zhang et al. developed a simple and novel analytical solution to calculate the amount of released energy due to varying joint density and derived a novel analytical solution to calculate the amount of released energy in coal with different joint densities [15].

Studying the failure mode of coal is important to explain the mechanism of coal mine dynamic disasters. Jiang et al. pointed out that the inner cracking of hard rock is the root factor for rock's large deformation and failure [16]. Deng et al. analyzed three types of cracks displayed by coal samples under static load by uniaxial compression system [17]. Wang et al. performed experimental tests under uniaxial cyclic load-unload conditions using a microcomputer-controlled electrohydraulic servo stiffness compressor with acoustic emission (AE) monitoring to show a meaningful attempt for predicting coal failure [18]. Li et al.'s qualitative and quantitative analysis of fractures in anthracites indicated that their damage evolution process could be divided into three phases under the uniaxial test and four phases under the triaxial test [19]. Liu et al. made research on the damage evolution mechanism of the overall creep failure process of coal rock under uniaxial and triaxial compression load [20]. Kong et al. performed dynamic impact experiments of gasbearing coal which showed that gas flow over the coal surface will increase shear stress along the fracture surface, in turn inducing coal fracture [21]. Li et al. set up a static load and static and dynamic combination load failure test simulation system, prepared with different particle sizes to study the characteristics of coal cracks produced in the vibration failure process [22]. Qin et al. conducted axial loading tests on three different types of rock specimens (coal, gritstone, and fine sandstone) and their composite specimens and found that, in the composite rock strata, a small amount of energy was stored, and energy accumulation was more difficult in competent rock with large elastic moduli [23].
Jiang et al. provided a new way to quantitatively assess a joint's shear damage [24]. Hao et al. studied the crack development pattern of the coal sample by the dynamic-static tensile experiment [25]. Yang et al. established a new nonlinear short-term and creep damage model of coal under conventional triaxial compression [26]. Gong et al. found that the symmetrical V-shaped failure modes on both sidewalls under the four stress conditions are in line with the statistical relationship of the far-field stress state and failure mode of a deep circular cavern without support [27].

From the above research, it can be found that current research into coal energy accumulation and release focuses on the factor of energy accumulation capacity and energy rate of release of coal, the theory of coal energy migration, and the development of the brittleness index. Aiming at the failure mode of coal, the research focuses on the initiation and development of cracks in the failure stage of coal and the description of its behavior after failure: however, few have studied the energy accumulation and release of coal under different loading conditions and different failure modes. These are important when trying to understand the mechanism of occurrence of, and preventive measures against, coal mine dynamic disasters.

In the present research, four experimental methods (uniaxial compression, Brazilian splitting, dynamic tension, and dynamic compression under coupled dynamic-static loading) were adopted to study the mechanical properties of coal under different load regimes. Through the analysis of the stress-strain curve and failure mode, the energy storage in, and release from, the coal body under different loading conditions were obtained. The analysis of coal failure modes under different loading conditions is of significance to the prevention and control of coal mine dynamic disasters.

\section{Experimental Programme}

To study the relationship between the mechanical properties of hard coal under static tensile, static compressive, dynamic tensile, and dynamic compressive loads, the classification of test specimens seen in Table 1 was adopted. The No. 14 coal in Xinzhouyao coal mine, Datong City, Shanxi Province, China, was selected. The sampled coal is shown in Figure 1. During the sampling process, the two ends of the sample are flattened to ensure that the two planes are parallel and perpendicular to the central axis. A total of 46 samples were processed in the experiment. After processing, 31 coal specimens with a height of $25 \mathrm{~mm}$ and a diameter of $50 \mathrm{~mm}$ were formed. Among them, three were used for static tensile strength testing, 12 for dynamic tensile strength testing, and 15 for dynamic compressive strength testing. At the same time, 15 specimens with a height of $50 \mathrm{~mm}$ and a diameter of $25 \mathrm{~mm}$ were formed for static compressive strength testing.

In order to obtain the stress-strain curve of static tensile, static compressive, dynamic tensile, and dynamic compressive of the samples, the relevant data are recorded in time during all the tests, and the crack propagation of the samples is obtained by high-speed camera in real time. The test instrument and the specific operation process are as follows. 
TABLE 1: Sample grouping and loading situation.

\begin{tabular}{lcc}
\hline Number & Dynamic loading & Test method \\
\hline B-1 B-2 C-7 F-1 F-3 F-4 D-1 & Dynamic compressive & None \\
D-3 D-4 D-5 E-1 E-2 E-3 E-4 E-7 & Dynamic compressive & $60 \%$ of the static compressive strength \\
A-1 A-3 A-6 A-7 & Dynamic tensile & None \\
B-4 B-5 B-6 B-7 & Dynamic tensile & $30 \%$ of the static tensile strength \\
C-1 C-2 C-5 C-6 & Dynamic tensile & $60 \%$ of the static tensile strength \\
Z1 Z2 Z3 Z4 Z5 Z6 F1 F2 F3 F4 F6 N1 N2 N3 N4 & None & Static compressive \\
S1 S2 S3 & None & Static tensile \\
\hline
\end{tabular}

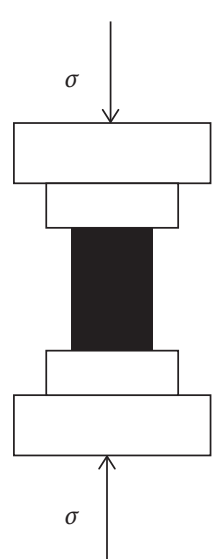

(a)

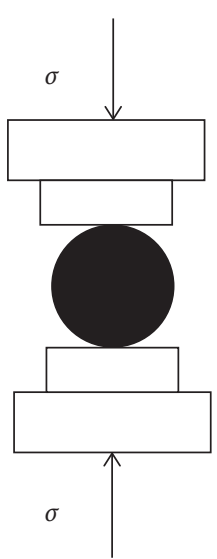

(b)

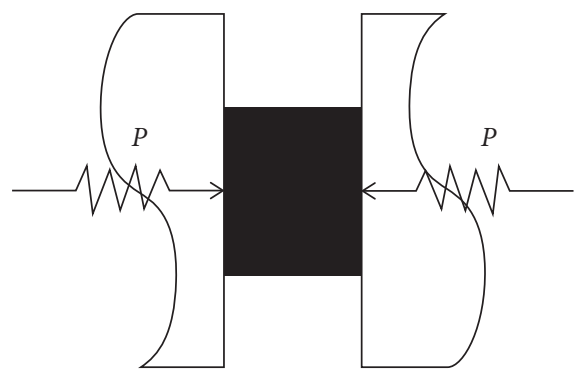

(c)

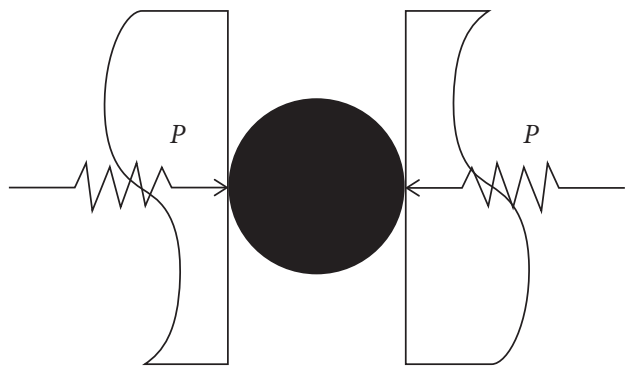

(d)

$\stackrel{\sigma}{\longrightarrow}$ Static load

$\stackrel{P}{P} \underset{\longrightarrow}{\longrightarrow}$ Dynamic load

FIGURE 1: Schematic diagram of different loading modes (in which, (a) represents the test of uniaxial compression, (b) represents the test of Brazilian split, (c) represents the test of dynamic tensile, and (d) represents the test of dynamic compressive).

To measure the static compressive strength of the samples, uniaxial compression tests were carried out on the MT815.04 rock mechanics experimental machine in the Institute of Rock and Soil Mechanics, Chinese Academy of Science. The loading rate of the machine is $5.0 \times 10^{-6} \mathrm{~mm} / \mathrm{s}$.

The WDW-100E microcomputer-controlled electronic universal testing machine was selected for Brazilian testing: displacement control was selected for load application at $0.02 \mathrm{~mm} / \mathrm{min}$.

The dynamic tensile test and dynamic compression test were conducted using the SHPB system of North China University of Science and Technology, and an axial pressure loading device was added at the end of the original SHPB experimental system to provide static axial prestress. In this experimental system, the diameters of the incident bar and transmission bar are both $50 \mathrm{~mm}$, the wave velocity is $5667 \mathrm{~m} / \mathrm{s}$, and the elastic modulus is $250 \mathrm{GPa}$.

\section{Test Results}

3.1. Static Tensile Test Results. The stress-strain curves of Brazilian static tensile samples are shown in Figure 2. It can be seen from the figure that the static tensile strength of the sample undergoes four stages: compaction, elasticity, yield, and failure. Among them, the compaction and linear elastic phase of the sample account for a large proportion, while the yield stage is very short. After reaching peak strength, the curve first drops rapidly and then rises slowly, but the amplitude change is not obvious, but then drops rapidly, showing a step-down change, and finally, the sample is destroyed.

The crack initiation and propagation characteristics of the sample during static tension in the Brazil test (as captured by camera) are shown in Figure 3. Each sample can be divided into seven stages to failure. With increasing load, the primary cracks in the sample are compacted, and the cracks appear in the sample, and then, the cracks widen and increase in length. With the continuous development of cracks, many cracks on the surface of the sample begin to penetrate, which leads to the penetrating fracture of the sample. Finally, when the load increases to a certain strength, the sample fails.

3.2. Static Compression Test. There are 15 groups of static compression test, and the stress-strain curves are shown in Figure 4 . The stress-strain curve of the static compression test is similar to that of the Brazilian static tensile stressstrain curve, which can be roughly divided into four stages: compaction, elasticity, yield, and failure. It can be seen that the compaction and linear elastic phase of the sample account for a large proportion, and the curve rises until it 


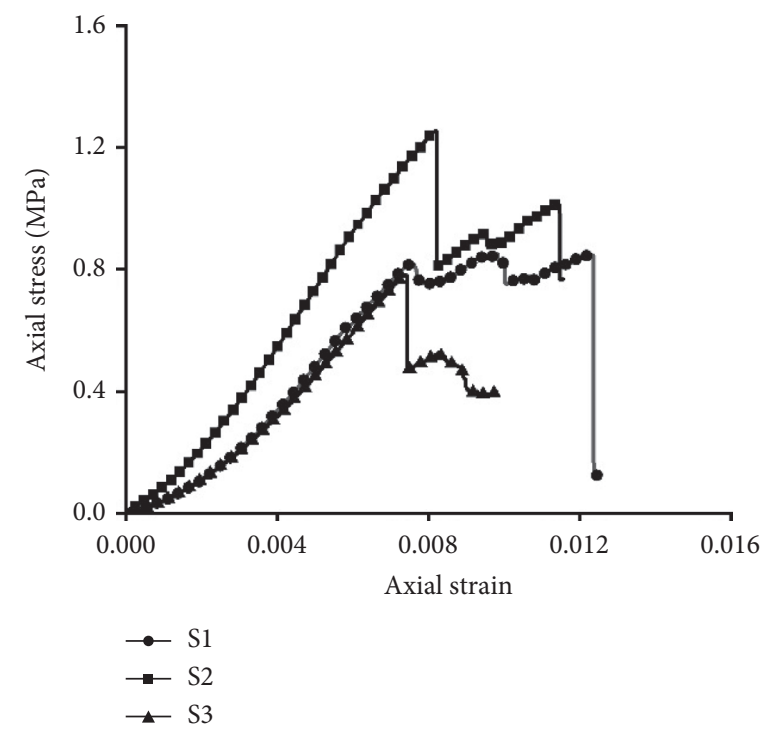

FIgURE 2: Stress-strain curve: static tensile test.

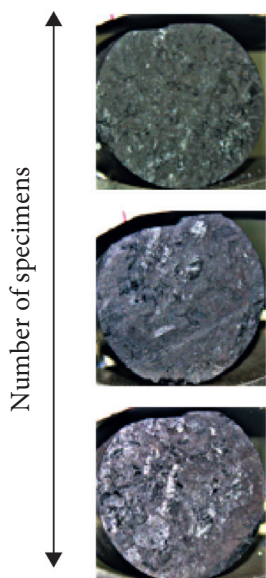

Start

loading
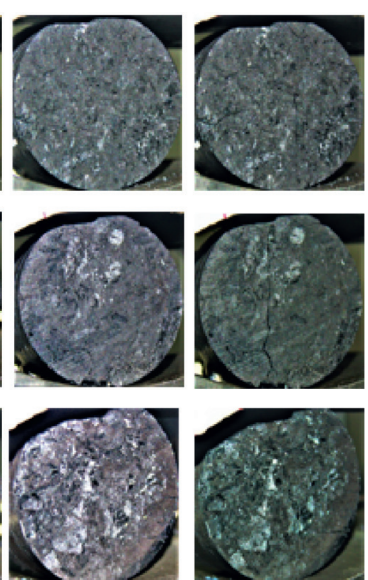

Crack

appearing

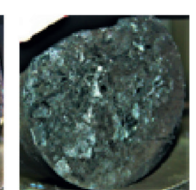

Crack widening
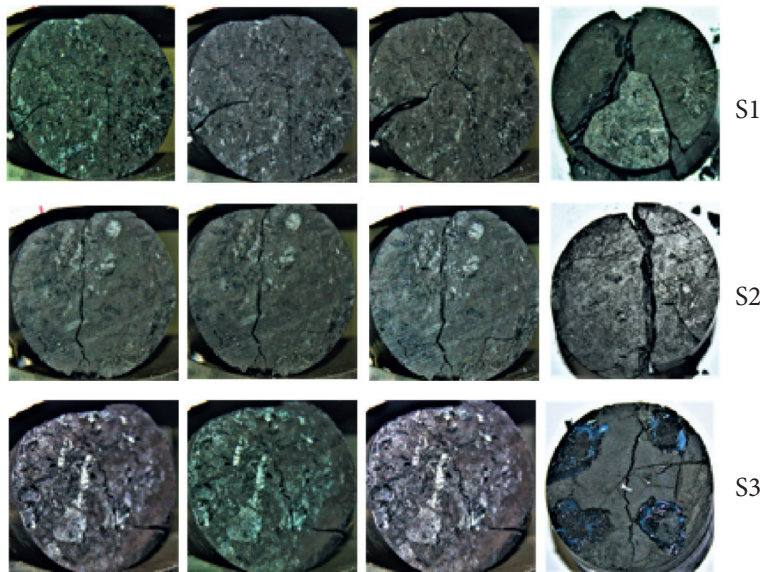

Crack

increasing

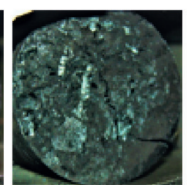

Crack penetration

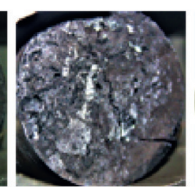

Penetrate fracture

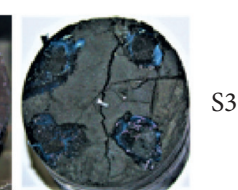

Specimens fragment

Fragment process

FIgURE 3: Typical static tensile crack initiation and propagation characteristics.

reaches the peak intensity; however, some specimens exhibited a small drop before reaching peak strength, such as specimens F2, F3, and N4. After reaching the peak intensity, the curves show a step-down drop. Finally, the sample is destroyed, and the bearing capacity dropped.

The crack initiation and propagation characteristics of the samples during static compression testing are shown in Figure 5. Each sample can be divided into five stages to failure. With increasing load, the primary cracks in the sample are compacted. There is no obvious crack on the surface of sample, but the sample expanded. With the gradual closure of primary cracks and the continuous expansion of the sample, cracks begin to appear on the surface of the samples. With increasing load, the cracks begin to penetrate. Finally, the load increases until reaching the strength of the sample at failure.
3.3. Results of Dynamic Tensile Strength Testing. The stressstrain curve of the coal sample dynamic tensile test is shown in Figure 6. Overall, as the strain of the coal sample continues to increase, the stress on the sample also continues to increase until it reaches the peak strength whereafter the drop is relatively gentle. And the prepeak rising rate of the dynamic tensile curve shows a downward trend with the increase of strain which is different from static tensile, and there is no step-down shape in the postpeak stage.

The characteristics of crack initiation and propagation of the sample in the dynamic tensile process are shown in Figure 7. In the process of dynamic tensile test, the sample can be divided into the following seven stages to failure. The picture shows specimens A-1, B-4, and C- 5 taken by highspeed cameras at different stages during the test. Take B-4 as an example: at $0 \mu \mathrm{s}$, the bullet penetrates the sample. At 


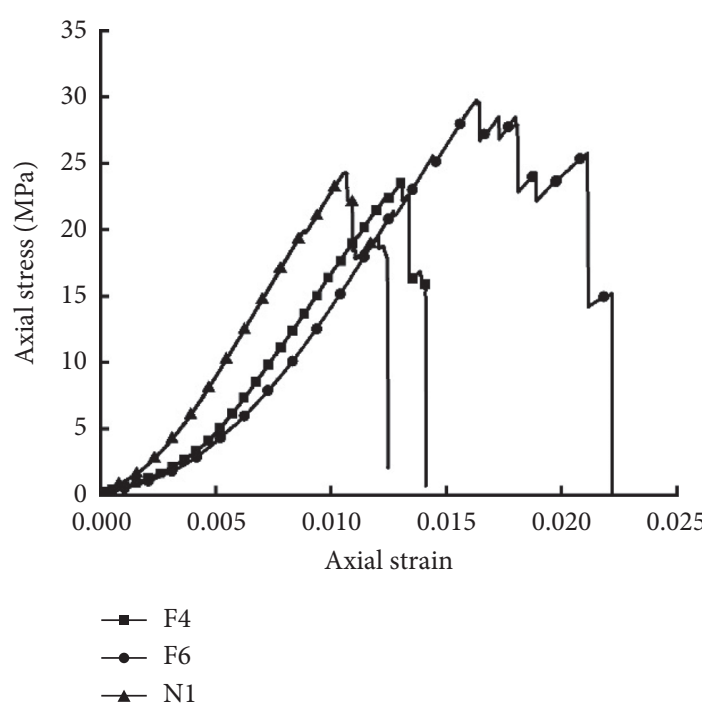

(a)
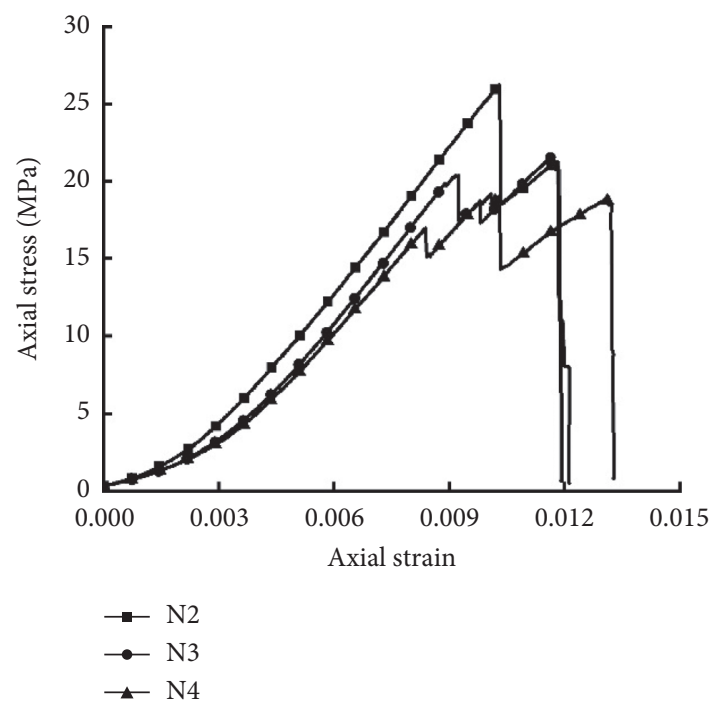

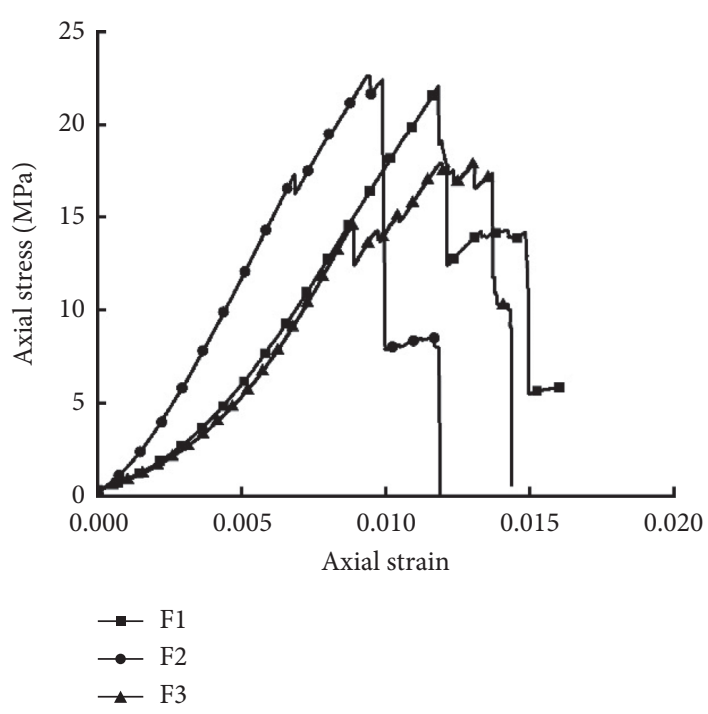

(b)

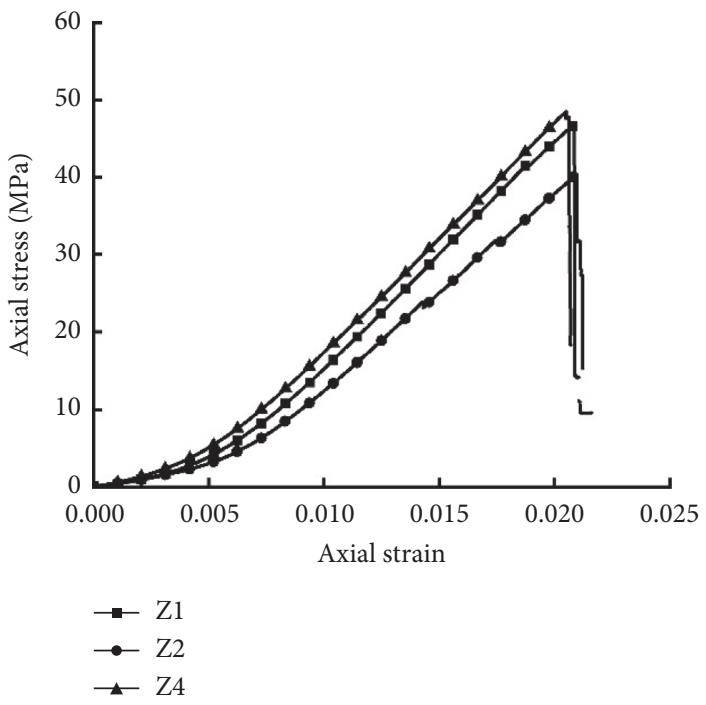

(d)

(c)

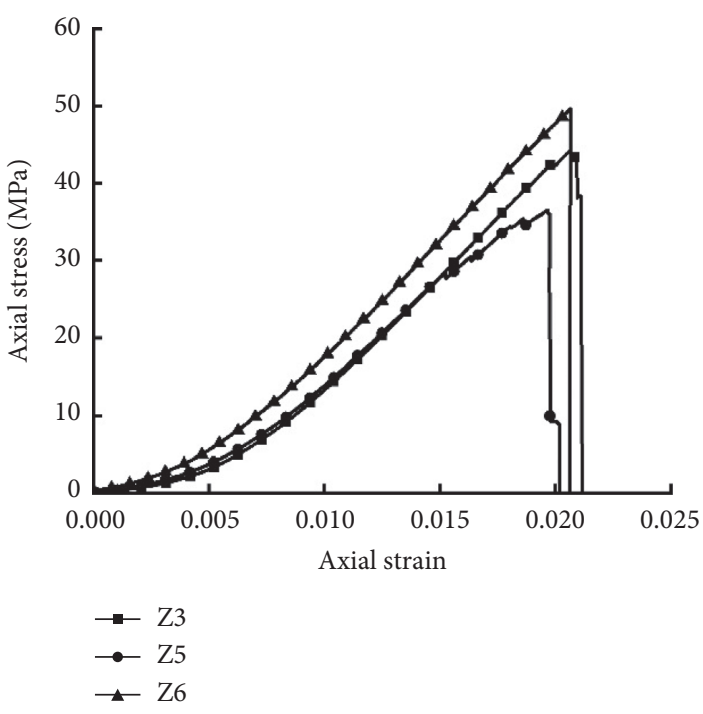

(e)

FIgURE 4: Stress-strain curve: static compression test. 


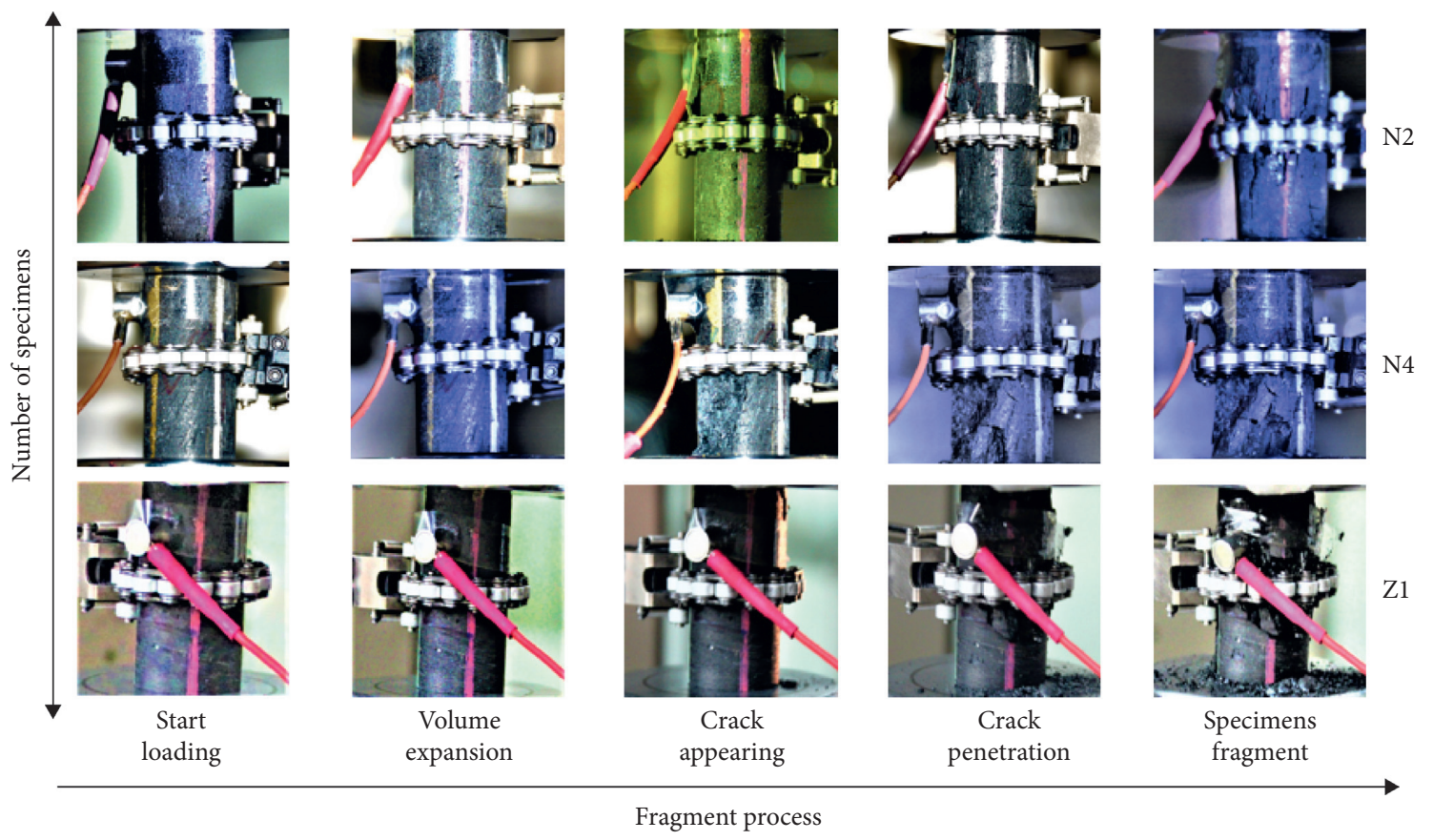

FIgURE 5: Typical static compression crack initiation and propagation characteristics.
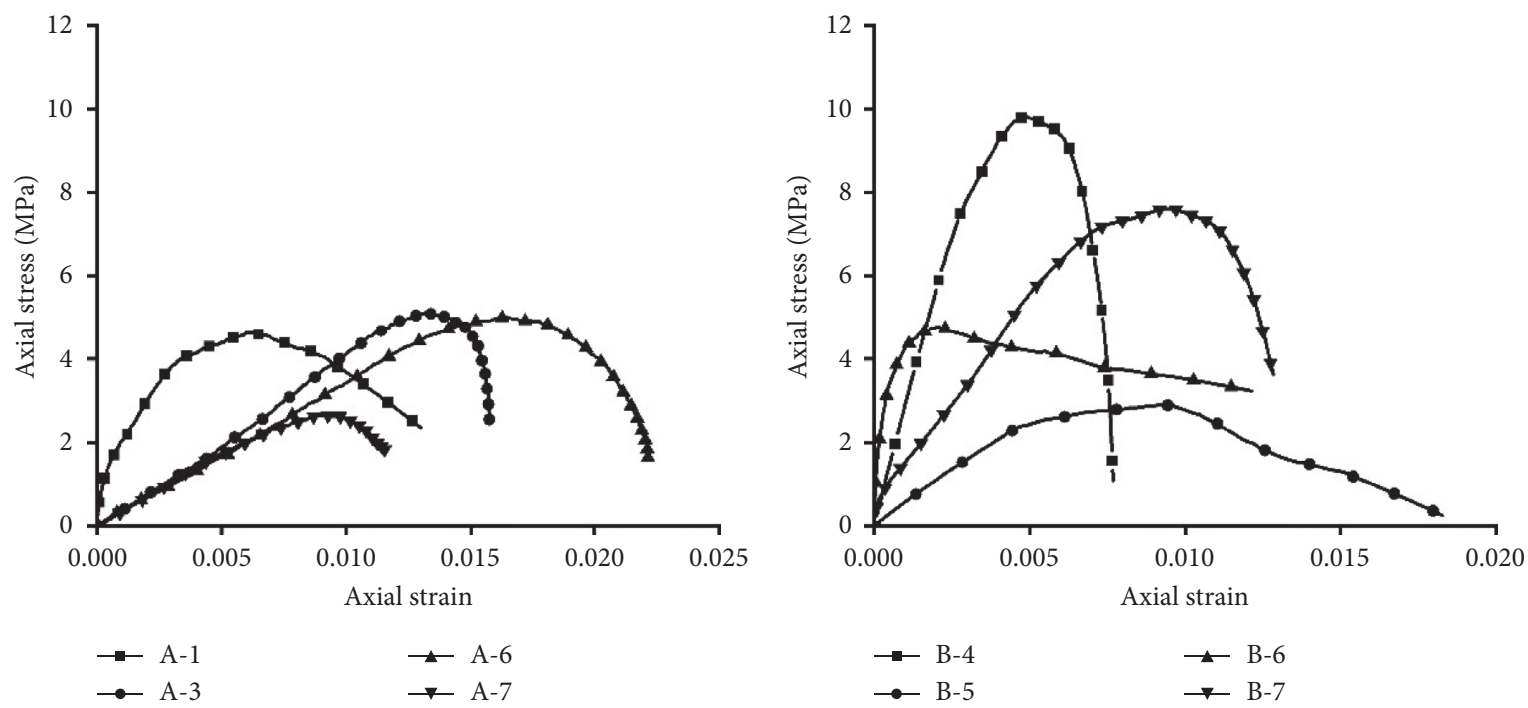

(a)

(b)

Figure 6: Continued. 


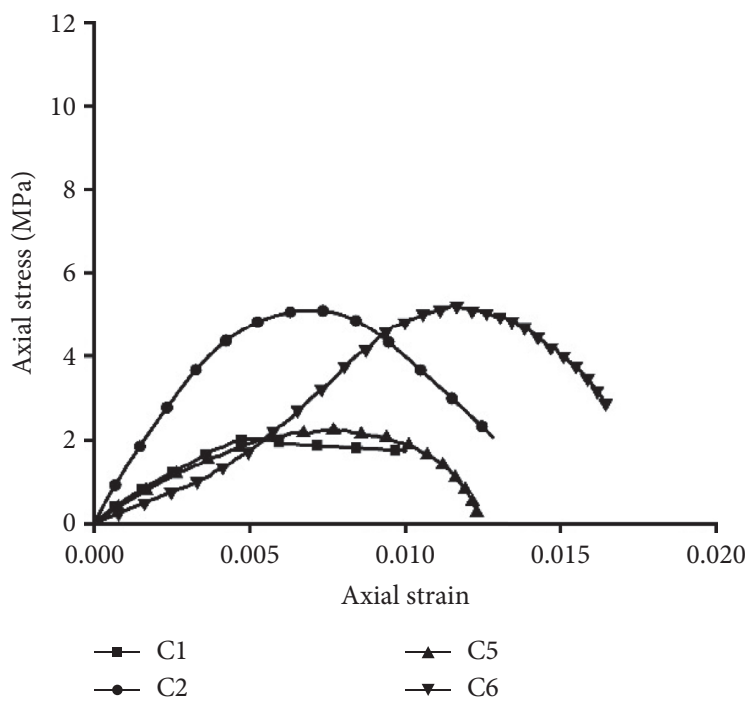

(c)

Figure 6: Stress-strain curve of the dynamic tensile test. (a) Axial static load of 0 MPa. (b) Axial static load of 0.289 MPa. (c) Axial static load of $0.578 \mathrm{MPa}$.

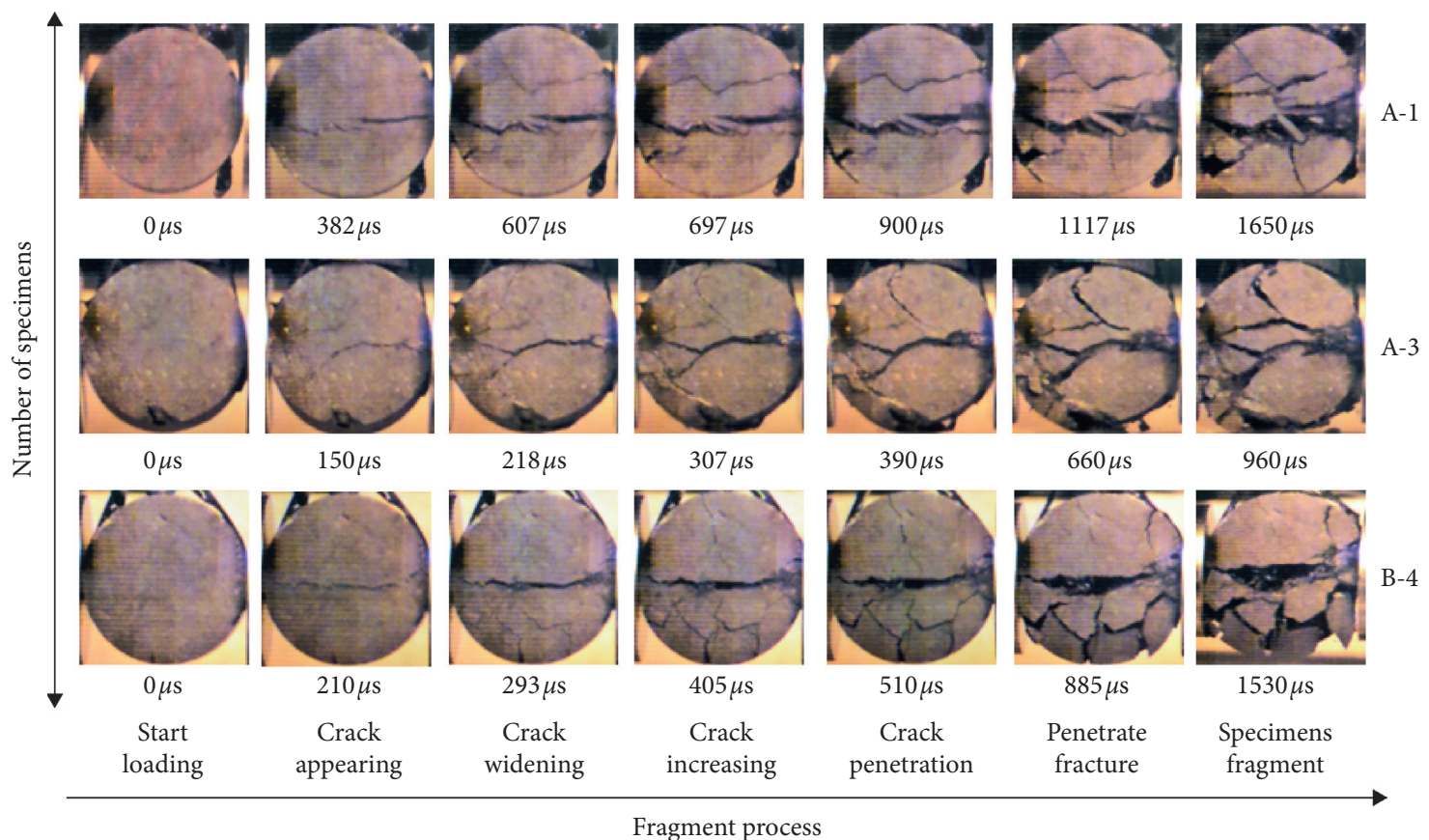

FIgURe 7: Typical dynamic tensile crack initiation and propagation characteristics.

$210 \mu \mathrm{s}$, crack initiation occurs; at $293 \mu \mathrm{s}$, the crack begins to widen; at $405 \mu \mathrm{s}$, the crack length begins to increase; at $405 \mu \mathrm{s}$, multiple cracks began to penetrate; at $885 \mu \mathrm{s}$, the sample broke through; and the sample failed at $1530 \mu \mathrm{s}$. From the occurrence of the first cracking to complete failure of the sample, it takes $1268 \mu$ s for sample A-1, $1320 \mu$ s for sample B-4, and $825 \mu$ s for sample C-5. According to the analysis of the dynamic tensile stress-strain curve, when the sample is subject to a static axial prestress of $30 \% \sigma_{t}$, the dynamic tensile strength of the coal sample is higher than when there is no static axial prestress and $60 \% \sigma_{t}$ static axial prestress, so the time to the destruction of sample B-4 is longer than that of samples A-1 and C-5, which corroborates the previous conclusions.

3.4. Results of Dynamic Compressive Strength Testing. The dynamic compressive stress-strain curve of the sample is shown in Figure 8. The dynamic compression curve shows an overall upward trend in the prepeak stage, and some samples (F-3, F-4) dropped slightly before reaching peak intensity. The curve drops slowly after reaching the peak, 

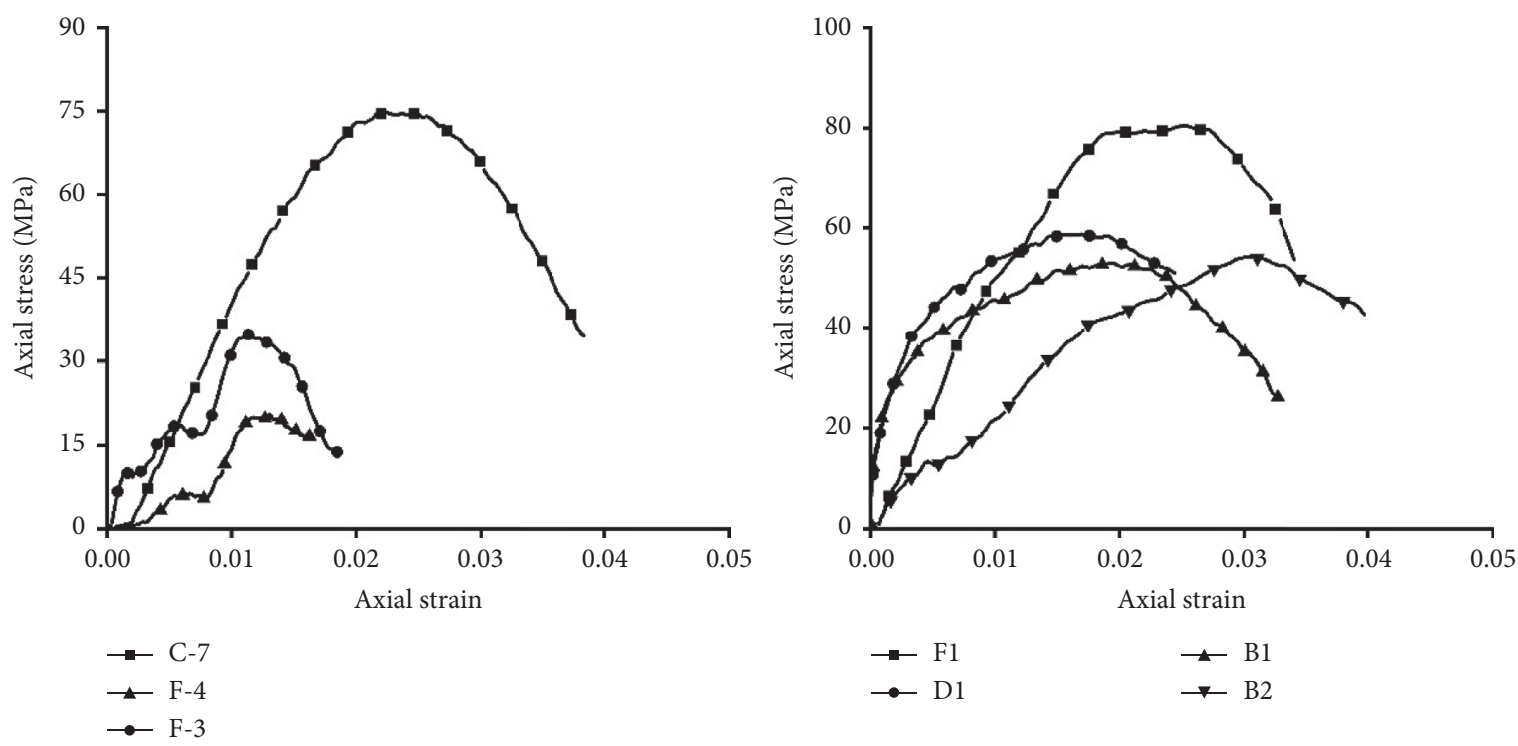

(a)
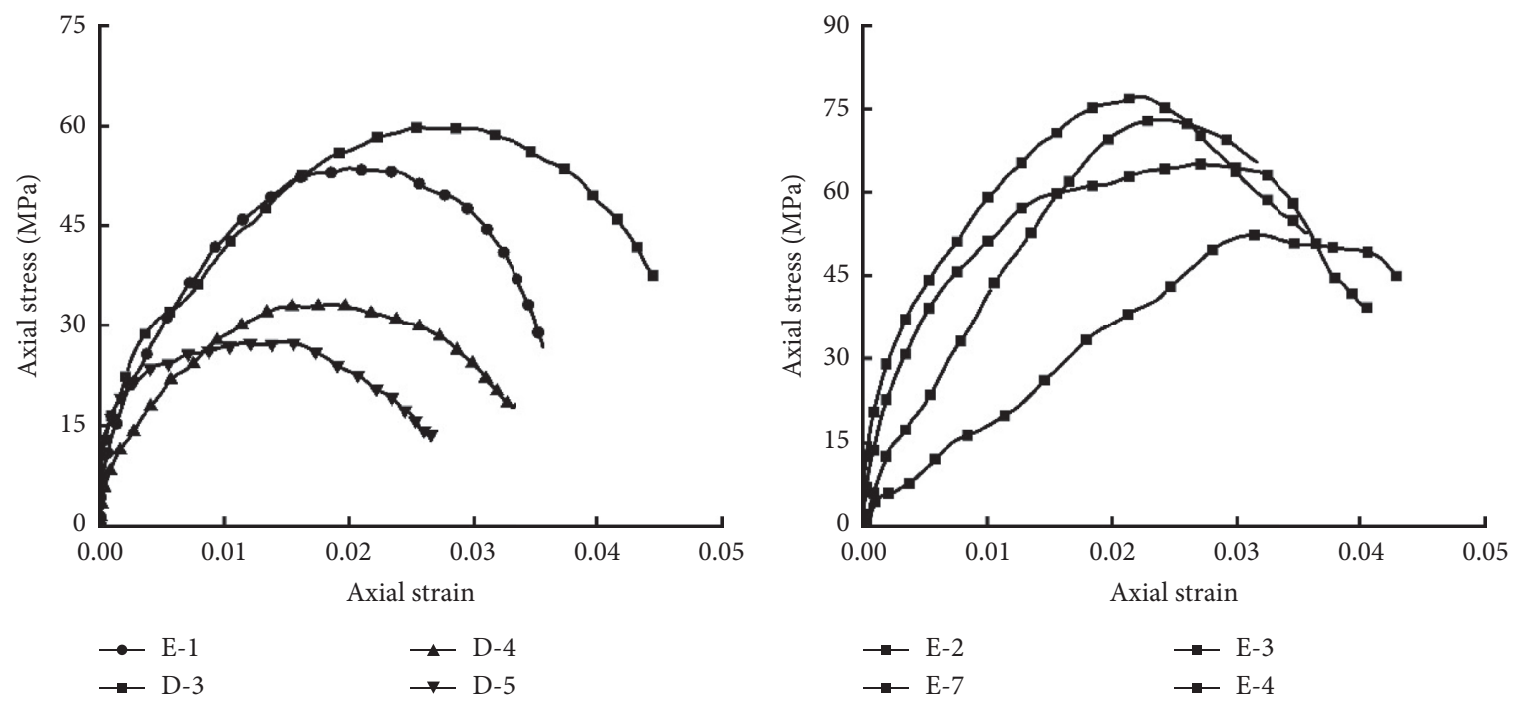

(b)

Figure 8: Stress-strain curve: dynamic compressive testing. (a) A static axial prestress of $0 \mathrm{MPa}$. (b) A static axial prestress of $12 \mathrm{MPa}$.

which is equivalent to the rising rate of the prepeak curve. Different from the static compressive curve, the prepeak rising rate of the dynamic compression curve shows a downward trend with the increase of strain, and there is no step-down shape in the postpeak stage.

The characteristics of crack initiation and propagation of the sample in the dynamic compression process are shown in Figure 9: the sample can be divided into the following five stages to failure. The picture shows specimens C-7, F-3, and F-4 (as captured by high-speed camera) at different stages during the test. Take F-3 as an example: at $0 \mu \mathrm{s}$, the bullet penetrates the sample. At $98 \mu \mathrm{s}$, crack initiation occurs. At $165 \mu \mathrm{s}$, the crack length begins to increase. At $315 \mu \mathrm{s}$, multiple cracks begin to penetrate, and at $743 \mu \mathrm{s}$, the sample failed. From the time of occurrence of cracking to the complete destruction of the sample, sample C-7 takes the shortest time, at only $750 \mu$ s; sample F-4 takes the longest time at $16,140 \mu \mathrm{s}$; and the time to failure for sample F-3 is $645 \mu$ s. It can be seen from Table 1 that sample C-7 has the highest impact velocity, followed by sample F-3, and sample F-4 has the lowest impact velocity. So it can be seen from Figure 9 that the greater the impact velocity, the shorter the sample failure time; and in each stage of sample failure, the greater the impact velocity, the greater the damage to the sample.

\section{Analysis}

4.1. Difference of the Stress-Strain Curve under Static and Dynamic Tensile. The stress-strain curve comparison between dynamic tensile tests (specimens A-1, A-3, A-6, and A-7) and static tensile tests (S1, S2, and S3) without static axial prestress is shown in Figure 10: the prepeak nonlinear elastic phase and linear elastic phase show that the dynamic tensile 


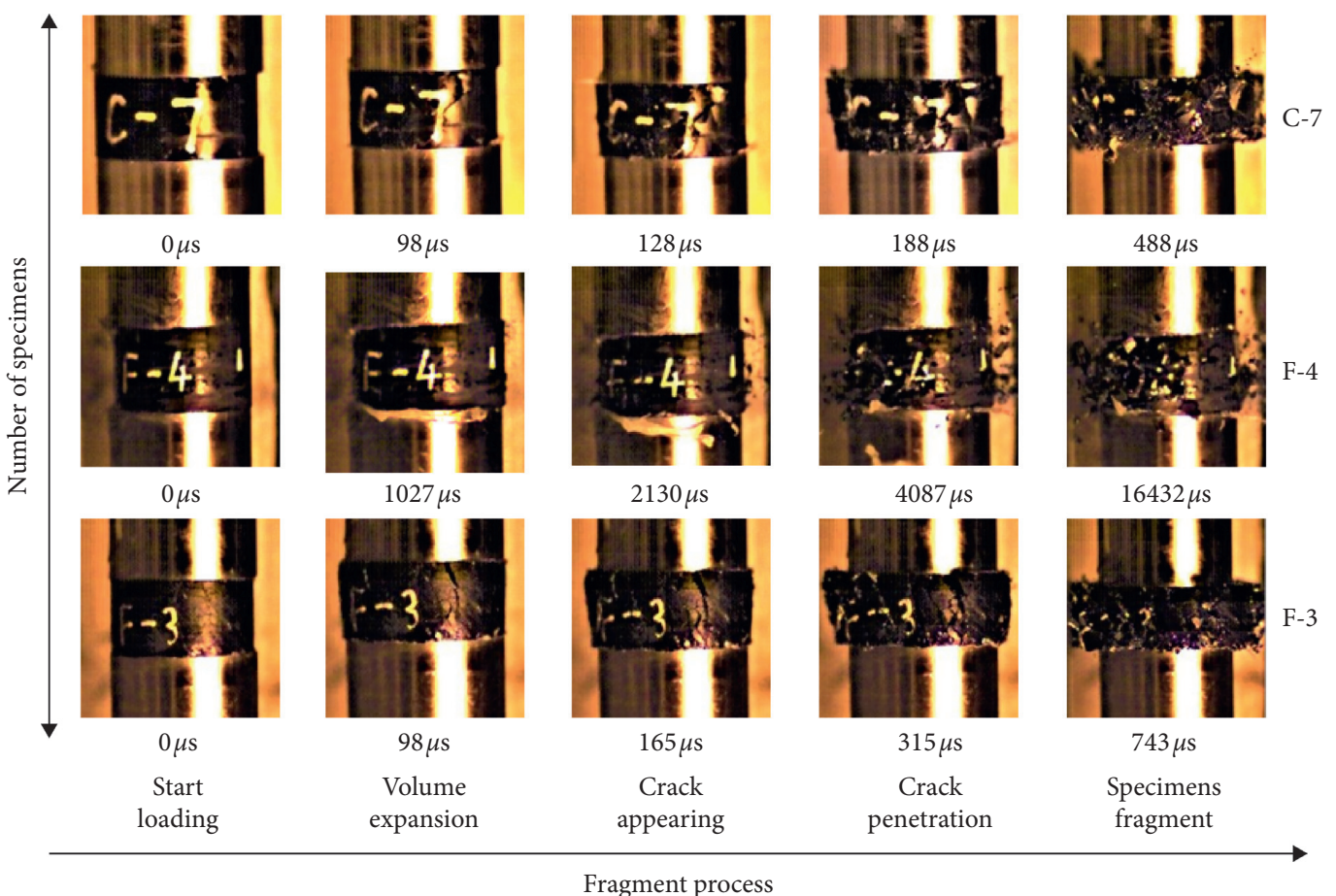

Figure 9: Typical dynamic compression crack initiation and propagation characteristics.

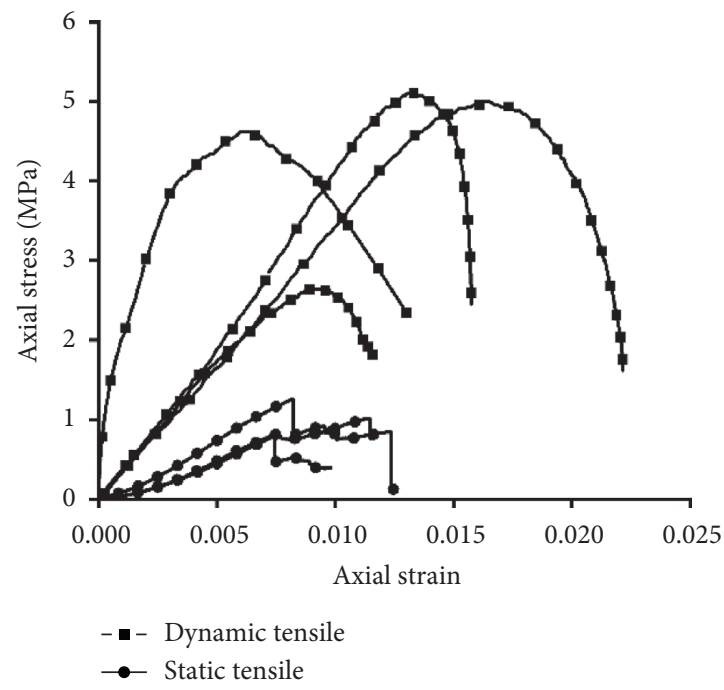

FIGURE 10: Comparison of dynamic and static tensile stress-strain curves.

curve lasts longer than the static tensile curve at the applied load rates, and the slope of the dynamic tensile curve decreases with increasing strain, while the slope of the static tensile curve increases with increasing strain. In the postpeak failure stage, the static tensile test data present a sharp drop and slow rise (a step-down shape), while the curve of dynamic tensile drops more slowly. The peak of the dynamic tensile curve appears at a strain of $0.005 \sim 0.016$, and the peak of the static tensile curve appears at a strain of $0.007 \sim 0.009$. The static tensile strength is between $0.08 \mathrm{MPa}$ and $0.13 \mathrm{MPa}$, and the dynamic tensile strength is between $2.5 \mathrm{MPa}$ and $5.5 \mathrm{MPa}$.
4.2. Difference in the Stress-Strain Curve under Static and Dynamic Compression. The comparative relationship between the dynamic compression curve and the static compression curve without static axial prestress is shown in Figure 11. In the prepeak nonlinear and linear elastic phases, the slope of the dynamic compression curve (F-1, B-1, D-1, and D-2) decreases with increasing strain, while the slope of the static compression curve (Z1, Z2, and Z4) increases with increasing strain. In the postpeak failure stage, the dynamic compression curve falls more gently, and the static compression curve shows a sharp drop or a step-down trend. The peak of the dynamic compression curve appears at a strain of 


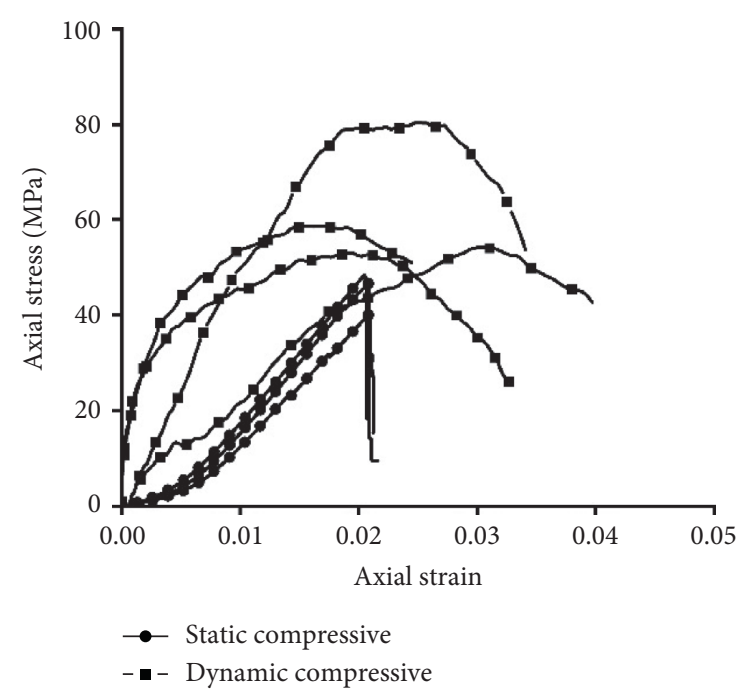

Figure 11: Comparison of dynamic and static compressive stressstrain curves.

0.015 0.035, and its average dynamic compressive strength is $61.95 \mathrm{MPa}$, while the peak of the static compression curve appears at a strain of $0.018 \sim 0.021$, and its average static compressive strength is $45.19 \mathrm{MPa}$. A comparison of the two sets of curves shows that the dynamic compressive strength of the coal sample is higher than the static compressive strength of the coal sample, and the strain at the peak of the dynamic compression curve is greater than the strain at the peak of the static compression curve.

\subsection{Differences of Crack Initiation and Propagation Processes} under Dynamic and Static Load. Comparing the crack initiation and propagation process of the static (Figure 3) and dynamic (Figure 7) tensile samples, it is found that all the samples have cracks in the loading direction at the crack appearance stage, but dynamic tensile test specimens have a greater degree of crack initiation than samples under static tensile load. At the crack widening stage, the crack width of the dynamic tensile sample is greater than the width of static tensile cracks, and in the loading direction, new small cracks are being generated under dynamic load. As cracking increases, the number of cracks in the dynamic tensile sample increases more than in static tensile samples, and cracks normal to the loading direction appear under dynamic load. At the crack penetration stage, the crack penetration of dynamic tensile samples was more severe. After failure, the dynamic tensile test specimens were broken into four or five pieces, and static tensile test specimens were broken into two pieces: the damage was more severe than that to static tensile test specimens.

Comparing the crack initiation and propagation process of the static (Figure 5) and dynamic (Figure 9) compression samples, it is found that, at the volume expansion stage, the volume expansion of the dynamic compression samples exceeded that of the static compression samples, and cracks have appeared at the tip of the force under dynamic loading. At the onset of cracking, the main crack that appears in the process of dynamic compression is longer and wider, and there are other small cracks generated around the main crack, while, in the static compression process, only one small main crack appears. At the crack penetration stage, the crack penetration of dynamic compression samples is more severe. After samples fail, the dynamic compression samples are broken into powders, while the static compression samples can retain their basic shape, and the degree of damage to dynamic compression test samples is more severe than that under static compression.

\section{Discussion}

The study of the prepeak energy accumulation and the postpeak rate of release of energy is of significance when trying to understand the mechanism underpinning coal mine dynamic disasters. According to the law of conservation of energy, the value of the work done by the external force on the object is equal to the magnitude of the energy change in the object. Therefore, the prepeak energy accumulation of the coal sample is equal to the work done by the press on the sample, that is, the prepeak energy accumulation of the coal; from the perspective of energy release, the magnitude of the unsteady rate of release of postpeak energy of the coal sample can be characterised by the absolute value of the slope of the line between the peak strength and the residual strength during the postpeak stress-drop (Figure 12 and Table 2).

\subsection{Comparison of Prepeak Energy Accumulation and Rate of Release of Coal}

5.1.1. Comparison of Energy Accumulation and Release under Static Tensile and Compressive Load. As can be seen from Table 2, the prepeak energy accumulation ranges from 0.085 to $0.42456 \mathrm{~J} \cdot \mathrm{m}^{-3}$ under static compression, and the average energy accumulation is $0.219 \mathrm{~J} \cdot \mathrm{m}^{-3}$; the prepeak energy accumulation ranges from 0.00236 to $0.00482 \mathrm{~J} \cdot \mathrm{m}^{-3}$ under static tension, and the average energy accumulation is $0.00387 \mathrm{~J} \cdot \mathrm{m}^{-3}$. The prepeak energy accumulation during static compression is much higher than the prepeak energy accumulation during static tension. The prepeak energy accumulation during static compression is 17.63-179.90 times the prepeak energy accumulation during static tension, with an average of a 56.59-fold increase. In terms of postpeak energy rate of release, the rate of release of static compression samples ranges from $5.2 \times 10^{3}-2.5 \times 10^{6}$, with an average of $2.0 \times 10^{5}$, while the rate of release of static tensile samples ranges from $1.9 \times 10^{2}-2.8 \times 10^{2}$, with an average of $2.3 \times 10^{2}$. The postpeak energy rate of release of static compressive samples is 18.57-13157.89 times the postpeak energy release of static tensile samples, with an average of 869.57 times. The comparison of the aforementioned data indicates that this type of hard coal can store more energy under compression than under tension.

5.1.2. Comparison of Energy Accumulation and Release under Dynamic Tension and Compression of Coal. As seen from Table 2, the prepeak energy accumulation ranges from 


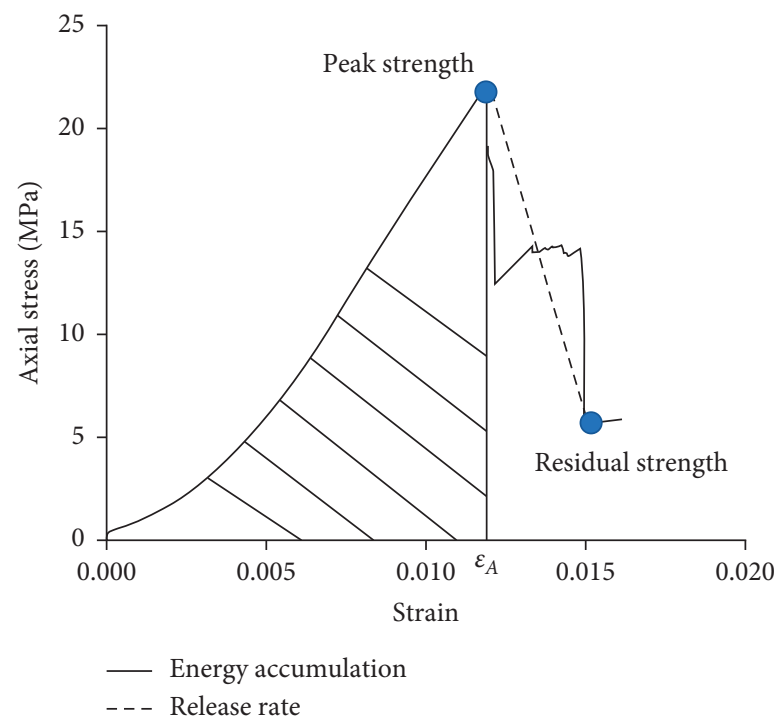

FIGURE 12: Mathematical model of calculation of energy accumulation and release rate.

0.00595 to $0.0482 \mathrm{~J} \cdot \mathrm{m}^{-3}$ during dynamic tension, with an average energy accumulation of $0.0234 \mathrm{~J} \cdot \mathrm{m}^{-3}$; the prepeak energy accumulation ranges from 0.1017 to $1.47878 \mathrm{~J} \cdot \mathrm{m}^{-3}$ during dynamic compression, with an average energy accumulation of $0.836 \mathrm{~J} \cdot \mathrm{m}^{-3}$. The energy accumulation during dynamic compression is greater that during dynamic tension. The prepeak energy accumulation during dynamic compression is 2.11-248.53 times the prepeak energy accumulation during dynamic tension, with an average of 35.72 times. Compared with the above conclusions, it is found that the ratio of prepeak energy accumulation to tensile prepeak energy accumulation is reduced by nearly 1.6 times during dynamic loading. In terms of postpeak energy release, the postpeak energy rate of release of dynamic compression ranges from $7.5 \times 10^{2}-2.9 \times 10^{3}$, with an average rate of release of $1.7 \times 10^{3}$, while the postpeak energy rate of release range of dynamic tensile samples ranges from $6.0 \times 10^{1}-3.2 \times 10^{3}$, with an average rate of release of $7.1 \times 10^{2}$. The postpeak energy rate of release under dynamic compression is $0.23-48$ times the postpeak energy rate of release under dynamic tension, with an average of 2.39 times. After a comparison of the above data, during dynamic loading, the energy stored in this type of hard coal under compression is still greater than that under tension.

\subsubsection{Comparison of Energy Accumulation and Release under} Different Loading Conditions for Coal. As seen from Table 2, the prepeak energy accumulation ranges from 0.01272 to $0.0441 \mathrm{~J} \cdot \mathrm{m}^{-3}$ during dynamic tension, with an average prepeak energy accumulation of $0.0279 \mathrm{~J} \cdot \mathrm{m}^{-3}$. The prepeak energy accumulation ranges from 0.00236 to $0.00482 \mathrm{~J} \cdot \mathrm{m}^{-3}$ during static tension, with an average prepeak energy accumulation of $0.00387 \mathrm{~J} \cdot \mathrm{m}^{-3}$. The dynamic tensile prepeak energy accumulation peak is 2.64-17.42 times the static tensile prepeak energy accumulation, with an average of 7.21 times. In terms of postpeak energy rate of release, the postpeak energy rate of release from dynamic tensile samples ranges from $3.0 \times 10^{2}-1.0 \times 10^{3}$, with an average rate of release of $5.66 \times 10^{2}$, while the rate of release from static tensile samples ranges from $1.9 \times 10^{2}-2.8 \times 10^{2}$, with an average of $2.3 \times 10^{2}$. The postpeak energy rate of release from dynamic tensile samples is 1.07-5.26 times that from static tensile samples, with an average of 2.41 times.

The prepeak energy accumulation ranges from 0.10171 to $1.27806 \mathrm{~J} \cdot \mathrm{m}^{-3}$ during dynamic compression, with an average prepeak energy accumulation of $0.714 \mathrm{~J} \cdot \mathrm{m}^{-3}$. The prepeak energy accumulation ranges from 0.085 to $0.42456 \mathrm{~J} \cdot \mathrm{m}^{-3}$ during static compression, with an average prepeak energy accumulation of $0.219 \mathrm{~J} \cdot \mathrm{m}^{-3}$. The dynamic compressive prepeak energy accumulation is $0.24-15.04$ times that of the static compressive prepeak energy accumulation, with an average of 3.26 times. In terms of postpeak energy rate of release, the postpeak energy rate of release from dynamic compressive samples ranges from $7.5 \times 10^{2}-2.9 \times 10^{3}$, with an average rate of release of $2.0 \times 10^{3}$, while the rate of release from static compressive samples ranges from $5.2 \times 10^{3}$ to $2.5 \times 10^{6}$, with an average of $2.0 \times 10^{5}$. The postpeak energy rate of release from dynamic compressive samples is 0.0003-0.56 times that from static compressive samples, with an average of 0.01 times.

A comparison of the above data shows that the energy accumulation increases in the case of dynamic loading; however, the increase in accumulated energy during dynamic tension is greater than that during dynamic compression (by about 2.21 times), which also confirms the conclusion in Section 5.1.2. The rate of release of energy during dynamic tension is greater than that during static tension, and the rate of release of energy during dynamic compression is lower than that during static compression.

5.1.4. Influence of Axial Prestress on the Energy Accumulation and Release. As shown in Table 2, when the axial prestress is zero, the dynamic tensile prepeak energy 
TABLE 2: Calculation results of energy accumulation and release rate under different loading states of coal.

\begin{tabular}{|c|c|c|c|c|c|c|c|}
\hline Number & $\begin{array}{l}\text { Axial } \\
\text { prestress } \\
(\mathrm{MPa}) \\
\end{array}$ & $\begin{array}{c}\text { Prepeak energy } \\
\text { accumulation }\left(\mathrm{J} \cdot \mathrm{m}^{-3}\right)\end{array}$ & $\begin{array}{c}\text { Unsteady release } \\
\text { rate of postpeak } \\
\text { energy }\end{array}$ & Number & $\begin{array}{l}\text { Loading } \\
\text { method }\end{array}$ & $\begin{array}{c}\text { Prepeak energy } \\
\text { accumulation }\left(\mathrm{J} \cdot \mathrm{m}^{-3}\right)\end{array}$ & $\begin{array}{c}\text { Unsteady release } \\
\text { rate of postpeak } \\
\text { energy }\end{array}$ \\
\hline \multicolumn{4}{|c|}{ Dynamic compressive } & \multicolumn{4}{|c|}{ Static compressive } \\
\hline B-1 & 0 & 0.81876 & $2.1 \times 10^{3}$ & $\mathrm{Z} 1$ & $\begin{array}{c}\text { Uniaxial } \\
\text { compression }\end{array}$ & 0.39206 & $5.2 \times 10^{4}$ \\
\hline B-2 & 0 & 0.91154 & $1.1 \times 10^{3}$ & $\mathrm{Z} 2$ & $\begin{array}{c}\text { Uniaxial } \\
\text { compression }\end{array}$ & 0.33203 & $5.1 \times 10^{4}$ \\
\hline $\mathrm{C}-7$ & 0 & 0.89884 & $2.5 \times 10^{3}$ & $\mathrm{Z3}$ & $\begin{array}{c}\text { Uniaxial } \\
\text { compression }\end{array}$ & 0.40908 & $1.8 \times 10^{4}$ \\
\hline F-1 & 0 & 1.27806 & $2.8 \times 10^{3}$ & $\mathrm{Z} 4$ & $\begin{array}{c}\text { Uniaxial } \\
\text { compression }\end{array}$ & 0.34479 & $1.2 \times 10^{4}$ \\
\hline F-3 & 0 & 0.19908 & $2.9 \times 10^{3}$ & $\mathrm{Z} 5$ & $\begin{array}{c}\text { Uniaxial } \\
\text { compression }\end{array}$ & 0.30413 & $2.1 \times 10^{5}$ \\
\hline F-4 & 0 & 0.1017 & $1.7 \times 10^{3}$ & Z6 & $\begin{array}{c}\text { Uniaxial } \\
\text { compression }\end{array}$ & 0.42456 & $2.5 \times 10^{6}$ \\
\hline D-1 & 0 & 0.79244 & $1.1 \times 10^{3}$ & F1 & $\begin{array}{c}\text { Uniaxial } \\
\text { compression }\end{array}$ & 0.10732 & $5.2 \times 10^{3}$ \\
\hline D-3 & $40 \% \sigma_{c}$ & 0.75666 & $1.7 \times 10^{3}$ & F2 & $\begin{array}{c}\text { Uniaxial } \\
\text { compression }\end{array}$ & 0.10201 & $9.0 \times 10^{3}$ \\
\hline D-4 & $40 \% \sigma_{c}$ & 0.49132 & $1.0 \times 10^{3}$ & F3 & $\begin{array}{c}\text { Uniaxial } \\
\text { compression }\end{array}$ & 0.11466 & $4.1 \times 10^{4}$ \\
\hline D-5 & $40 \% \sigma_{c}$ & 0.37796 & $1.3 \times 10^{3}$ & $\mathrm{~F} 4$ & $\begin{array}{c}\text { Uniaxial } \\
\text { compression }\end{array}$ & 0.12371 & $5.5 \times 10^{4}$ \\
\hline E-1 & $40 \% \sigma_{c}$ & 1.25233 & $1.4 \times 10^{3}$ & F6 & $\begin{array}{c}\text { Uniaxial } \\
\text { compression }\end{array}$ & 0.18963 & $5.0 \times 10^{3}$ \\
\hline E-2 & $40 \% \sigma_{c}$ & 1.22993 & $1.8 \times 10^{3}$ & N1 & $\begin{array}{c}\text { Uniaxial } \\
\text { compression }\end{array}$ & 0.11253 & $1.2 \times 10^{4}$ \\
\hline E-3 & $40 \% \sigma_{c}$ & 1.47878 & $2.1 \times 10^{3}$ & $\mathrm{~N} 2$ & $\begin{array}{c}\text { Uniaxial } \\
\text { compression }\end{array}$ & 0.11452 & $1.6 \times 10^{4}$ \\
\hline E-4 & $40 \% \sigma_{c}$ & 0.86412 & $7.5 \times 10^{2}$ & $\mathrm{~N} 3$ & $\begin{array}{c}\text { Uniaxial } \\
\text { compression }\end{array}$ & 0.12217 & $3.3 \times 10^{4}$ \\
\hline E-7 & $40 \% \sigma_{c}$ & 1.08444 & $1.1 \times 10^{3}$ & $\mathrm{~N} 4$ & $\begin{array}{c}\text { Uniaxial } \\
\text { compression }\end{array}$ & 0.08508 & $5.4 \times 10^{3}$ \\
\hline \multicolumn{4}{|c|}{ Dynamic tensile } & \multicolumn{4}{|c|}{ Static tensile } \\
\hline A-1 & 0 & 0.02 & $3.2 \times 10^{2}$ & $\mathrm{~S} 1$ & Brazil split & 0.00442 & $2.8 \times 10^{2}$ \\
\hline A-3 & 0 & 0.03463 & $1.0 \times 10^{3}$ & S2 & Brazil split & 0.00482 & $1.9 \times 10^{2}$ \\
\hline A-6 & 0 & 0.0441 & $5.7 \times 10^{2}$ & S3 & Brazil split & 0.00236 & $2.2 \times 10^{2}$ \\
\hline A-7 & 0 & 0.01272 & $3.0 \times 10^{2}$ & \multicolumn{4}{|c|}{ Dynamic tensile } \\
\hline B-4 & $30 \% \sigma_{t}$ & 0.03015 & $3.2 \times 10^{3}$ & $\mathrm{C}-1$ & $60 \% \sigma_{t}$ & 0.00595 & $6.0 \times 10^{1}$ \\
\hline B-5 & $30 \% \sigma_{t}$ & 0.01809 & $2.9 \times 10^{2}$ & $\mathrm{C}-2$ & $60 \% \sigma_{t}$ & 0.02353 & $5.2 \times 10^{2}$ \\
\hline B-6 & $30 \% \sigma_{t}$ & 0.00772 & $1.5 \times 10^{2}$ & C-5 & $60 \% \sigma_{t}$ & 0.01023 & $4.0 \times 10^{2}$ \\
\hline B-7 & $30 \% \sigma_{t}$ & 0.04553 & $1.1 \times 10^{3}$ & C-6 & $60 \% \sigma_{t}$ & 0.02801 & $4.6 \times 10^{2}$ \\
\hline
\end{tabular}

accumulation ranges from 0.01272 to $0.0441 \mathrm{~J} \cdot \mathrm{m}^{-3}$, with an average prepeak energy accumulation of $0.0279 \mathrm{~J} \cdot \mathrm{m}^{-3}$. The postpeak rate of release of energy ranges from $3.0 \times 10^{2}-1.0 \times 10^{3}$, with an average of $5.6 \times 10^{2}$. When the axial prestress is $30 \% \sigma_{t}$, the dynamic tensile prepeak energy accumulation ranges from 0.00772 to $0.04553 \mathrm{~J} \cdot \mathrm{m}^{-3}$, with an average of $0.0254 \mathrm{~J} \cdot \mathrm{m}^{-3}$. The postpeak rate of release of energy ranges from $1.5 \times 10^{2}-3.2 \times 10^{3}$, with an average of $1.2 \times 10^{3}$. When the axial prestress is $60 \% \sigma_{t}$, the dynamic tensile prepeak energy accumulation ranges from 0.00595 to $0.02801 \mathrm{~J} \cdot \mathrm{m}^{-3}$, with an average of $0.0169 \mathrm{~J} \cdot \mathrm{m}^{-3}$. The postpeak energy rate of release ranges from $5.0 \times 10^{1}-5.2 \times 10^{2}$, with an average of $3.6 \times 10^{2}$. In the case of dynamic tension, for this type of hard coal, the prepeak energy accumulation gradually decreases with increasing axial prestress within a certain range. The postpeak rate of release of energy increases with the axial prestress within a certain range and decreases with the increase of axial prestress after exceeding a certain threshold.

When the axial prestress is zero, the prepeak energy accumulation during dynamic compression ranges from 0.19908 to $1.27806 \mathrm{~J} \cdot \mathrm{m}^{-3}$, with an average of $0.714 \mathrm{~J} \cdot \mathrm{m}^{-3}$. The postpeak rate of release of energy ranges from $1.1 \times 10^{3}-2.9 \times 10^{3} \mathrm{~J} \cdot \mathrm{m}^{-3}$, with an average of $2.0 \times 10^{3} \mathrm{~J} \cdot \mathrm{m}^{-3}$. When the axial prestress is $40 \% \sigma_{c}$, the prepeak energy accumulation during dynamic compression ranges from 0.37796 to $1.47878 \mathrm{~J} \cdot \mathrm{m}^{-3}$, with an average of $0.942 \mathrm{~J} \cdot \mathrm{m}^{-3}$. The postpeak rate of release of energy ranges from $7.5 \times 10^{2}-2.1 \times 10^{3}$, with an average of $1.4 \times 10^{3}$. In the case of dynamic compression, for this type of hard coal, the prepeak 
energy accumulation gradually increases with the axial prestress within a certain range. The postpeak rate of release of energy decreases with increasing of axial prestress beyond a certain threshold.

\section{Conclusion}

In the present research, the prepeak energy accumulation and postpeak energy release behaviors of this type of hard coal under different loading conditions are obtained. Combining the aforementioned data with the failure mode of the sample, the conclusions are as follows:

(1) Under static loading, for this type of hard coal, the static compression prepeak energy accumulation is 17.63-179.90 times that under static tension. The static compression postpeak rate of release of energy is $18.57-13157.89$ times that under static tension.

(2) Under dynamic loading, for this type of hard coal, the dynamic compression prepeak energy accumulation is $2.11-248.53$ times that under dynamic tension. The dynamic compression postpeak energy release rate is 0.23-48 times that under dynamic tension.

(3) During dynamic loading, the compression prepeak energy accumulation and postpeak energy release rate are both greater than that under tension, but the ratio of energy accumulation in compression to that under tension is 1.6 times lower than that under static load. The ratio of compression postpeak energy release rate to that under tension is 363.84 times lower than that under static load.

(4) The dynamic tensile prepeak energy accumulation, for this type of hard coal, is 2.64-17.42 times that under static tensile load. The dynamic tensile postpeak energy release rate is $1.07-5.26$ times that under static tensile load. Under dynamic tension, the prepeak energy accumulation and the postpeak energy release rate both increase compared with that under static tension.

(5) The dynamic compressive prepeak energy accumulation is $0.24-15.04$ times the static compressive energy accumulation. The dynamic compressive postpeak energy release rate from the specimen is 0.0003-0.56 times that under static compression. Under dynamic compression, the prepeak energy accumulation increases compared with that under static compression, and the postpeak energy release rate is lower than that under static compression.

(6) The order of the damage degree of this type of hard coal sample is dynamic compression, static compression, dynamic tension, and static tension. Which is the same as the order of the prepeak energy accumulation. It shows that the prepeak energy accumulation is positively related to the damage degree of the coal sample. The greater the prepeak energy accumulation, the greater the degree of damage of the coal sample, also the higher the degree of fragmentation after the failure.

\section{Data Availability}

The data used to support the findings of this study are included within the article.

\section{Conflicts of Interest}

The authors declare that they have no conflicts of interest.

\section{Acknowledgments}

This article was supported by the National Natural Science Foundation of China (no. 51804309), the Yue Qi Young Scholar Project (2019QN02) and Distinguished Scholar Project (2017JCB02) from China University of Mining and Technology (Beijing), Open Fund of State Key Laboratory of Water Resource Protection and Utilization in Coal Mining (Grant no. SHJT-17-42.10), the fund of Beijing Outstanding Young Scientist Program (BJJWZYJH01201911413037), and Natural Science Foundation of China (nos. U1910206, and 51861145403).

\section{References}

[1] F. Gong, J. Yan, X. Li, and S. Luo, "A peak-strength strain energy storage index for rock burst proneness of rock materials," International Journal of Rock Mechanics and Mining Sciences, vol. 117, pp. 76-89, 2019.

[2] F. Cui, Z. R. Zhao, Y. F. Du, Y. Bai, C. Q. Xu, and X. F. Jia, "Research on the correction for seismic multi-attribute prediction errors of small structures using GPR data: a case study in 1226 working face of Shuguang Coal Mine, Shanxi, China," Applied Geophysics, vol. 17, no. 3, 2020.

[3] F. L. He, X. M. Wang, D. Q. Zhang, and S. S. He, "Study on parameters of support for control of roof fall and rib spalling in large fully mechanized top coal caving end face," Advanced Materials Research, vol. 616-618, pp. 421-425, 2013.

[4] T. D. Le and X. N. Bui, "Effect of key parameters on top coal first caving and roof first weighting in longwall top coal caving: a case study," International Journal of Geomechanics, vol. 20, no. 5, Article ID 04020037, 2020.

[5] X. Wu, Y. Peng, J. Xu, Q. Yan, W. Nie, and T. Zhang, "Experimental study on evolution law for particle breakage during coal and gas outburst," International Journal of Coal Science \& Technology, vol. 7, no. 1, pp. 97-106, 2020.

[6] W. H. Zhang, Y. M. Chen, T. J. Ren, and Z. H. Qiu, "Disaster index of gas energy released during coal/gas outbursts,"vol. 4, pp. 217-224, in Proceedings of the 2004 International Symposium on Safety Science and Technology, vol. 4, Geotechnical Engineering Institute, Zhejiang University, Hangzhou, China, 2004.

[7] C. Wu, Y. Qin, and X. Fu, "Stratum energy of coal-bed gas reservoir and their control on the coal-bed gas reservoir formation," Science in China Series D: Earth Sciences, vol. 50, no. 9, pp. 1319-1326, 2007.

[8] C. Zhang, I. Canbulat, and B. F. HebblewhiteTahmasebinia, "Assessment of energy release mechanisms contributing to coal burst," International Journal of Mining Science and Technology, vol. 27, no. 1, pp. 43-47, 2017.

[9] O. Vardar, C. Zhang, F. Tahmasebinia et al., "DEM analysis of the effect of discontinuities on coal mass brittleness," in Proceedings of the 3rd International Conference on Rock 
Dynamics and Applications (RocDyn-3), Trondheim, Norway, June 2018.

[10] X. J. Hao, L. Yuan, Y. D. Guo et al., "A new brittleness index for hard coal considering unsteady energy release at post-peak stage," Chinese Journal of Rock Mechanics and Engineering, vol. 36, no. 11, pp. 2641-2649, 2017.

[11] Y. Tang, J. S. Okubo, and S. Peng, "Study on the progressive failure characteristics of coal in uniaxial and triaxial compression conditions using 3D-digital image correlation," Energies, vol. 11, no. 5, p. 1215, 2018.

[12] Z. P. Zhang, H. P. Xie, R. Zhang et al., "Deformation damage and energy evolution characteristics of coal at different depths," Rock Mechanics and Rock Engineering, vol. 52, no. 5, pp. 1-13, 2018.

[13] T. Lan, C. Fan, H. Zhang et al., "Seepage law of injected water in the coal seam to prevent rock burst based on coal and rock system energy," Advances in Civil Engineering, vol. 2018, Article ID 8687108, 19 pages, 2018.

[14] J. J. Feng, E. Y. Wang, X. Chen et al., "Energy dissipation rate: an indicator of coal deformation and failure under static and dynamic compressive loads," International Journal of Mining Ence and Technology, vol. 28, no. 3, pp. 397-406, 2018.

[15] C. G. Zhang, F. Tahmasebinia, I. Canbulat et al., "Analytical determination of energy release in a coal mass," Energies, vol. 11, no. 2, p. 285, 2018.

[16] Q. Jiang, X. T. Feng, S. Li, G. H. Su, and Y. X. Xiao, "Crackingrestraint design method for large underground caverns with hard rock under high geostress condition and its practical application," Chinese Journal of Rock Mechanics and Engineering, vol. 38, no. 6, pp. 1081-1101, 2019.

[17] X. Q. Deng, X. F. Liu, and S. C. Tian, "Experimental study of original cracks features effecting on fracture of coal samples under uniaxial compression," Procedia Engineering, vol. 26, pp. 681-688, 2011.

[18] C. Wang, Z. X. Hou, and Z. Z. LuChen, "Experimental investigation of predicting coal failure using acoustic emission energy and load-unload response ratio theory," Journal of Applied Geophysics, vol. 161, pp. 76-83, 2019.

[19] Y. Y. Li, H. Q. Cui, P. Zhang et al., "Three-dimensional visualization and quantitative characterization of coal fracture dynamic evolution under uniaxial and triaxial compression based on $\mu$ CT scanning," Fuel, vol. 262, 2019.

[20] B. X. Liu, Z. L. Shu, J. J. Han et al., "Real-time CT experimental research on creep microscopic damage evolution of coal rock under compression," Disaster Advances, vol. 5, no. 4, pp. 667-674, 2012.

[21] X. Kong, E. Wang, X. He et al., "Mechanical characteristics and dynamic damage evolution mechanism of coal samples in compressive loading experiments," Engineering Fracture Mechanics, vol. 210, pp. 160-169, 2018.

[22] C. W. Li, D. H. Ai, X. Y. Sun et al., "Crack identification and evolution law in the vibration failure process of loaded coal," Journal of Geophysics \& Engineering, vol. 4, no. 4, pp. 975-986, 2017.

[23] Z. Qin, J. B. Chen, and G. H. Zhang, "Tests on the dynamic failure rules of coal-rock composites," Acta Geodynamica et Geomaterialia, vol. 16, no. 1, pp. 39-54, 2019.

[24] Q. Jiang, B. Yang, F. Yan, C. Liu, Y. Shi, and L. Li, "New method for characterizing the shear damage of natural rock joint based on 3D engraving and 3D scanning," International Journal of Geomechanics, vol. 20, no. 2, Article ID 06019022, 2020.

[25] X. J. Hao, W. S. Du, Y. X. Zhao et al., "Dynamic tensile behaviour and crack propagation of coal under coupled static- dynamic loading," International Journal of Mining Ence and Technology, vol. 30, no. 5, 2020.

[26] S.-Q. Yang, P. Xu, and P. G. Ranjith, "Damage model of coal under creep and triaxial compression," International Journal of Rock Mechanics and Mining Sciences, vol. 80, pp. 337-345, 2015.

[27] F.-q. Gong, X.-f. Si, X.-b. Li, and S.-y. Wang, "Experimental investigation of strain rockburst in circular caverns under deep three-dimensional high-stress conditions," Rock Mechanics and Rock Engineering, vol. 52, no. 5, pp. 1459-1474, 2019. 